\title{
A questão racial na política brasileira (os últimos quinze anos)
}

\author{
ANTONIO SÉRGIO ALFREDO GUIMARĀES
}

RESUMO: Neste artigo, analiso o modo como a questão racial tem marcado a política brasileira nos últimos quinze anos. Começo expondo o que significou a idéia de democracia racial no processo de construção da nacionalidade brasileira, para depois, com a brevidade que o espaço exige, resenhar os estudos sobre o comportamento eleitoral dos negros brasileiros e tratar da emergência de movimentos sociais negros e de sua incorporação ao sistema político. Meu entendimento é que devemos ver na "democracia racial" um compromisso político e social do moderno estado republicano brasileiro, que vigeu, alternando força e convencimento, do Estado Novo de Vargas até o final da ditadura militar. Tal compromisso, hoje em crise, consistiu na incorporação da população negra brasileira ao mercado de trabalho, na ampliação da educação formal, enfim na criação das condições infra-estruturais de uma sociedade de classes que desfizesse os estigmas criados pela escravidão. A imagem do negro enquanto povo comum e o banimento, no pensamento social brasileiro, do conceito de "raça", substituído pelos de "cultura" e "classe social", são as expressões maiores desse compromisso.

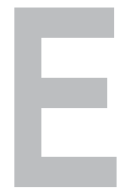

ste é um tema que pode, sem dúvida, ser tratado de diferentes perspectivas. Pode, primeiramente, referir-se ao modo como assuntos relativos às diferenças raciais da população brasileira são tratados ou abordados pelos políticos e pelas políticas públicas. Pode, também, reportar-se à maneira como algumas minorias raciais se organizam politicamente, seja em termos da construção de um sentimento étnico particular, seja em termos institucionais e partidários. $\mathrm{Ou}$, final-

PALAVRAS-CHAVE: democracia racial, movimento negro, questão racial, Brasil.

Professsor do Departamento de Sociologia da FFLCH - USP 
Texto preparado para a conferência "Fifteen years of democracy in Brazil", University of London, Institute of Latin American Studies, London, 15 and 16 February 2001. Agradeço comentários feitos a versões anteriores por Brasílio SaIlum, Lilia Schwarcz, Nadya Guimarães e Peter Fry. mente, pode aludir à forma particular com que diferentes contingentes raciais foram absorvidos numa única identidade nacional brasileira.

A ciência política brasileira construiu, todavia, no decorrer dos anos, um certo modo de abordar a questão. Bolívar Lamounier (1968) e Amaury de Souza (1971) arrolam três questões substantivas para estudo na relação entre raça e política no Brasil. A primeira é se negros e brancos têm comportamentos políticos diferenciais, presumidamente baseados na experiência das desigualdades sociais; a segunda é se há um comportamento político coletivo por parte dos negros, que expresse solidariedade racial; e finalmente, "como opera o sistema político para desmobilizar o potencial de comportamento político coletivo". Souza e a maioria dos que escreveram sobre a relação entre raça e política no Brasil (Silva e Soares, 1985; Castro, 1992; Berquó e Alencastro, 1992; Prandi, 1996) restringiram seus estudos à primeira dessas questões, enquanto Lamounier ateve-se a examinar a terceira. Tentarei abordar, brevemente, as três questões.

Entretanto, creio que a discussão, tal como esboçada acima, deve, no Brasil, enfrentar um primeiro desafio - o de demonstrar a existência de uma questão racial. Ainda que a nação brasileira tenha-se formado a partir da mesma matriz colonial americana, ou seja, do transplante de povos europeus para as Américas em situação de domínio sobre as populações indígenas aqui encontradas e sobre o também grande contingente de africanos escravizados, ainda assim, digo, acredita-se, em geral, numa certa excepcionalidade brasileira, que teria superado as diferenças raciais originais. Isso porque a solução brasileira ao problema da integração dos ex-escravos negros e de descendentes dos povos indígenas à sociedade nacional passou, primeiro, por negar a existência de diferenças biológicas (capacidades inatas), políticas (direitos), culturais (etnicidade) e sociais (segregação ou preconceito) entre esses e os descendentes de europeus, com ou sem misturas, e, em segundo lugar, por incorporar todas essas diferenças originais numa única matriz sincrética e híbrida, tanto em termos biológicos, quanto culturais, sociais e políticos. É o que se convencionou chamar de democracia racial.

Para desenvolver o tema deste artigo, portanto, sinto-me obrigado a demonstrar que a excepcionalidade brasileira é parte do problema, ou seja, trata-se de uma solução política historicamente datada, que se encontra em plena transformação.

Começarei, então, por situar historicamente o processo de construção da identidade nacional brasileira, no qual enquista-se a "solução" primeira da questão racial, para em seguida, com a brevidade que o espaço exige, resenhar os estudos sobre o comportamento eleitoral dos negros brasileiros e, depois, tratar da emergência de movimentos sociais negros e de sua incorporação ao sistema político. Darei, em todos esses tópicos, uma ênfase especial às mudanças registradas nos últimos quinze anos.

Comecemos, pois, por compreender a incorporação simbólica dos negros na comunidade nacional. É o que faremos a seguir. 


\section{A democracia racial brasileira}

A modernidade brasileira é, sem dúvida, produto dos últimos setenta anos. Os sociólogos e cientistas políticos demarcam, geralmente, tal modernidade com a Revolução de 1930, que pôs fim à Primeira República (1889-1929). Se em relação ao Império (1823-1889), a Primeira República procurou modernizar o Brasil através da adoção de novas instituições, da europeização dos costumes (Freyre, 1936) e do incentivo à emigração européia (Seyferth, 1990, Schwarcz, 1993), em continuidade com aquele, manteve uma nacionalidade ostensivamente polarizada, marcada pela enorme distância entre brancos e pretos, civilizados e matutos. Foi apenas a partir de 1930, principalmente com o Estado Novo (1937-1945) e a Segunda República (19451964), que o Brasil ganhou definitivamente um "povo", ou seja, inventou para si uma tradição e uma origem ${ }^{1}$.

A idéia fundamental da nova nação é a de que não existem raças humanas, com diferentes qualidades civilizatórias inatas, mas existem, sim, diferentes culturas. $O$ Brasil passa a se pensar a si mesmo como uma civilização híbrida, miscigenada, não apenas européia, mas produto do cruzamento entre brancos, negros e índios ${ }^{2}$. O “caldeirão étnico” brasileiro seria capaz de absorver e abrasileirar as tradições e manifestações culturais de diferentes povos que para aqui imigraram em diferentes épocas; rejeitando apenas aquelas que fossem incompatíveis com a modernidade (superstições, animismos, crendices, etc.). Tal idéia permite o cultivo de uma "alta cultura" propriamente brasileira em sintonia com a "cultura popular", algo que eclode na Semana de Arte Moderna de $1922^{3}$. Mas, de certo modo, foram as ciências sociais, e não apenas as artes plásticas e a literatura ficcional, as inventoras desse Brasil moderno, através de obras seminais como as de Gilberto Freyre (1933 e 1936), Sérgio Buarque de Holanda (1936) e Caio Prado Jr. ([1937]*1965).

As bases materiais e econômicas dessa modernidade foram plantadas pela Revolução de 1930. Essas consistem, basicamente, no incentivo à indústria e à substituição da mão-de-obra estrangeira por mão-de-obra brasileira, que passa a constituir propriamente um proletariado, com estatuto político reconhecido e regulado.

De fato, se a importação de cerca de 5 milhões de africanos abasteceu o mercado de trabalho da colônia (1560 a 1823) e do jovem estado independente durante o seu primeiro século de existência (1823 a 1852), a partir da extinção do tráfico de escravos a Europa passa a ser a principal região de abastecimento de mão-de-obra para a agricultura de exportação e para a indústria nascente. Estima-se em 4 milhões a emigração européia para o Brasil, constituída principalmente por portugueses, italianos e espanhóis, entre 1850 e 1932. Essa mão-de-obra estrangeira, concentrada quase totalmente em São Paulo, nos estados do sul e no Rio de Janeiro, dominou a oferta de mão-de-obra industrial e artesanal, alijando completamente do mercado a população negra e mestiça.
* A data entre colchetes refere-se à edição original da obra. Ela é indicada na $1^{\mathrm{a}}$ vez que a obra é citada. Nas demais, indica-se somente a edição utilizada pelo autor (N.E.)

1 Sigo, grosso modo, a interpretação de Freyre. É bem verdade, como nos diz Schwarcz (2000), que a europeização dos costumes iniciase com o Império. Mas, esta foi contrabalançada pelo romantismo brasileiro, em busca de nativismo; que, por sua vez, nunca foi amplo o suficiente para incorporar as massas negras e mulatas. $\mathrm{O}$ povo brasileiro, tal como hoje o concebemos, é uma construção modernista.

2 Esta é, entretanto, uma tradição intelectual que remonta ao final do século XIX, e que tem entre seus expoentes intelectuais do porte de Silvio Romero (1949) e Joaquim Nabuco (1883).

Esta interpretação deve, de novo, ser matizada com a compreensão de que o romantismo brasileiro revelou-se bastante artificial, ao excluir negros e mulatos do imaginário nacional. 
O fim da emigração estrangeira, nos anos 30, e a constituição de uma reserva de mercado para o trabalhador brasileiro, possibilitaram a incorporação de uma enorme massa racialmente miscigenada ou negra, que migrou para São Paulo e para os estados do sul e do sudeste brasileiro, oriunda de várias partes do país, principalmente de Minas Gerais, do interior de São Paulo, do Rio de Janeiro e dos estados do nordeste, as regiões mais populosas.

Até então, ou seja, até os anos 30, o Brasil tinha reconhecidamente uma questão racial, cujos fundamentos eram biológicos e demográficos. Assim, enquanto perdurou a importação de escravos africanos ou enquanto o volume de migração européia foi diminuto, éramos vistos por nossas elites como uma nação sem povo e sem uma cultura nacional (Skidmore, 1976).

Quando começa a emigração européia, é a ameaça de divisão cultural do país que passa a ser percebida, tal como colocada de modo exemplar por Nina Rodrigues, ainda no final do séc. XIX:

"Ao brasileiro mais descuidado e imprevidente não pode deixar de impressionar a possibilidade da oposição futura, que já se deixa entrever, entre uma nação branca, forte e poderosa, provavelmente de origem teutônica, que se está constituindo nos estados do Sul, donde o clima e a civilização eliminarão a Raça negra, ou a submeterão, de um lado; e, de outro lado, os estados do Norte, mestiços, vegetando na turbulência estéril de uma inteligência viva e pronta, mas associada à mais decidida inércia e indolência, ao desânimo e por vezes à subserviência, e assim ameaçados de converterem-se em pasto submisso de todas as explorações de régulos e pequenos ditadores" (Rodrigues, 1933, p. 19).

Ou seja, temia-se pela qualidade do estoque populacional brasileiro, temia-se a ausência de uniformidade cultural e temia-se pela unidade nacional, todos os temores sendo alimentados por crenças raciais.

Vargas, na política; Freyre, nas ciências sociais; os artistas e literatos modernistas e regionalistas, nas artes; esses serão os principais responsáveis pela "solução" da questão racial, diluída na matriz luso-brasileira e mestiça de base popular, formada por séculos de colonização e de mestiçagem biológica e cultural, em que o predomínio demográfico e civilizatório dos europeus nunca fora completo a ponto de imporem a segregação dos negros e mestiços. Ao contrário, a estratégia dominante sempre fora de "transformismo" e de "embranquecimento", ou seja, de incorporação dos mestiços socialmente bem sucedidos ao grupo dominante "branco".

Se a Primeira República fora responsável pela europeização dos costumes brasileiros e pela introdução de milhões de europeus no sul e no sudeste do Brasil, em detrimento da população mestiça, oriunda do caldei- 
rão colonial, a Revolução de 30 e a Segunda República tiveram o bom senso de desarmar a bomba étnica que se formava em conformidade com os temores de Nina Rodrigues.

A democracia racial, enquanto "solução" da questão negra, não significou, todavia, um esforço em combater as desigualdades de renda e de oportunidades sociais entre negros e brancos, e só parcialmente, no plano da cultura e da ideologia, representou um freio à discriminação e ao preconceito. Em termos jurídicos, por exemplo, apenas uma lei, em 1952, a Lei Afonso Arinos, reconheceu a existência de preconceito racial no país, punindo-o como contravenção legal, ainda que a sua prática continuasse disseminada e sem coibição. Todavia, há de se reconhecer que, em termos ideológicos, as crenças na democracia racial e na origem mestiça do povo brasileiro serviram para solidificar a posição formal de igualdade dos negros e mulatos na sociedade brasileira.

Mas nem mesmo foi a democracia racial suficiente para calar o protesto social dos negros, como veremos a seguir. Antes, porém, algumas palavras devem ser ditas sobre as tensões por que passa a "democracia racial" nos últimos quinze anos.

Se as migrações internas e a criação de uma sólida cultura nacional, de bases mestiças e populares, de origens principalmente nordestinas, baianas, cariocas e mineiras, foram capazes de desarmar a bomba étnica que se formava em São Paulo antes dos anos 30, elas não evitaram, porém, a emergência ou continuidade de novos problemas, tais como o preconceito racial e regional e as crescentes desigualdades raciais. Do mesmo modo, a crença na democracia racial fora tecida por sobre a lenda da excepcionalidade brasileira, que deixava de ser plausível à medida que outras sociedades pós-coloniais, como Estados Unidos e Canadá, superavam a segregação racial através de soluções como o convívio multirracial e multicultural, numa situação de convivência democrática mais igualitária em termos de oportunidades de vida.

Mais ainda. A democracia racial acabara por associar-se em demasia ao sentimento de nacionalidade, à ideologia oficial do regime militar e à expansão econômica dos anos 50, 60 e 70. O esgotamento do modelo econômico de substituição de importações e a débâcle do autoritarismo, que conduziram à grave crise dos anos 80 , erodiram assim as bases mesmas do sentimento de nacionalidade e de seus mitos. À crise econômica e à crise de governabilidade corresponderam sentimentos de desmoralização e desagregação nacionais. $\mathrm{O}$ Brasil começou a experimentar fenômenos até então desconhecidos ou já devidamente apagados da memória nacional, todos à contra-mão de seus mitos fundadores: a) a reivindicação de etnicidades indígenas por parte de populações de há muito integradas à vida nacional como caboclas; b) a imigração de grandes contingentes de brasileiros para o exterior, principalmente para os Estados Unidos, à procura de uma nova vida; c) o surgimento de movimentos separatistas no sul do país, assim como de atentados racistas contra negros e nordestinos, em São Paulo; d) a busca de dupla nacionalidade (um segundo passaporte) por parte da classe média branca de origem européia recente. 
Ou seja, o Brasil, para os brasileiros, pela primeira vez no pósguerra, já não era nem o melhor, nem o único, ao menos em termos de organização social. A grande expansão da educação formal e do mercado de trabalho, nas décadas anteriores, desaguava agora num enorme sentimento de frustração. As diferenças entre os brasileiros ficaram também mais visíveis.

Como tal sentimento manifestou-se entre a população negra? Comecemos pelo voto.

\section{O voto negro e a ciência política}

Focalizando especificamente São Paulo, entre 1888 e 1988, George Andrews (1991) apresenta uma interpretação síntese de quais têm sido as tendências políticas dos negros brasileiros. Seu argumento é que, no passado, a simpatia política do povo negro sempre esteve com a monarquia, pois era sabido que o Imperador sempre fora muito mais propenso à abolição da escravidão que os fazendeiros. Do mesmo modo, a Primeira República, que se segue à abolição, por ser uma república de fazendeiros, no plano do poder, e ter adotado uma política cultural de europeização dos costumes, nunca fora bem vista ou bem-quista pelos negros ${ }^{4}$. Apenas o Estado Novo de Getúlio Vargas, com sua política de proteção ao trabalhador brasileiro e de tutela de seus sindicatos (e, posteriormente, o trabalhismo de Getúlio, Jango e Brizola), reconquistou as simpatias das massas negras na mesma escala conseguida pela casa imperial.

Andrews reproduz em sua síntese o consenso de boa parte da literatura disponível sobre o tema.

A primeira tentativa de explicar o comportamento político diferenciado dos negros no Brasil moderno foi de Gilberto Freyre. As duas frases reproduzidas abaixo sintetizam muito bem a sua opinião sobre a preferência dos negros pelos políticos populistas, principalmente pelo trabalhismo.

"O lado irônico do desaparecimento simultâneo das duas instituições - escravidão e monarquia - foi que antigos escravos se encontraram na posição de homens e mulheres que não tinham o imperador nem o autocrata da casa-grande para protegê-los, tornando-se, em conseqüência, vítimas de profundo sentimento de insegurança. (...) Foram necessários anos para que os líderes políticos entendessem a situação psicológica e sociológica real destes antigos escravos, disfarçados em trabalhadores livres

${ }^{4}$ Esta linha de argumentação, seguida por Freyre e pelos cientistas políticos, é posta em cheque por Lilia Schwarcz (1999). e privados de assistência social patriarcal que lhes era dada na velhice ou na doença pela casa-grande ou, quando esta deixava de fazer-lhes justiça, pelo Imperador, pela Imperatriz ou Princesa imperial” (Freyre, 1956, p. 46). 
"Isto explica - chegando ao Brasil moderno - a grande popularidade de Getúlio Vargas quando, como presidente, por algum tempo com poder ditatorial, decidiu-se a implantar a legislação social que deu a grande parte da população obreira do Brasil proteção contra a velhice, doença e exploração por empresas comerciais ou industriais. Isto também explica porque Vargas se tornou conhecido como o "Pai dos Pobres" e conquistou entre o povo popularidade que superou a obtida por D. Pedro II em 48 anos de governo bom, honesto e paternalista” (Freyre, 1956, p. 46).

Bolívar Lamounier (1968) inaugura certamente uma nova tradição científica no estudo das relações entre raça e política no Brasil ao traçar uma agenda de investigação que comporta três grandes temas: a) comportamento eleitoral diferencial entre brancos e negros; b) organização política coletiva autônoma dos negros; c) formas de integração dos negros no sistema político. Para Lamounier, a situação brasileira oferece um aparente paradoxo: grandes e crescentes desigualdades sociais entre brancos e negros convivem lado a lado com a relativa ausência de conflitos violentos e com a quase inexistência de assuntos raciais na esfera política. Sem tratar em detalhe o primeiro dos temas arrolados, mas aceitando a observação de Freyre de que os negros, mais que os brancos, apóiam os líderes trabalhistas e populistas, Lamounier concentra-se no último dos temas para oferecer uma explicação para o paradoxo por ele apontado. Para ele, primeiro, o Estado brasileiro tem sido capaz de gerar símbolos de integração e incorporação dos negros que são suficientes para contrabalançar as tensões oriundas do preconceito e da discriminação raciais; segundo, o Estado tem sabido antecipar-se ou abortar no nascedouro as tensões raciais; terceiro, as instituições sociais brasileiras têm tido sucesso em cooptar as lideranças negras emergentes e agressivas.

Mas, foi Amaury de Souza (1971) quem demonstrou pela primeira vez, utilizando-se da técnica de análise multivariada, a partir de dados eleitorais, controlando seja a classe social, a educação, seja outras variáveis de posição social, que os negros apresentavam realmente comportamento político diferente dos brancos, comprovando o que já tinha sido avançado por Freyre em termos impressionísticos. Daí em diante, a interpretação de que o voto negro concentrava-se em políticos populistas, ao menos no que se refere ao período republicano, passa a ser ancorada em pesquisas empíricas de intenção de votos.

Voltemos a Souza (1971). Depois que ele demonstrou que os negros, nas eleições de 1960, votaram mais consistentemente em Jango que os brancos, independentemente de sua situação sócio-econômica, firma-se na ciência política brasileira a idéia de um certo padrão de voto negro, que iria sistematicamente em direção aos populistas e trabalhistas. Uma década depois, Gláucio Soares e Nelson do Valle Silva (Silva \& Soares, 1985), analisando a vitória de Brizola 
nas eleições para governador do Rio de Janeiro, demonstram fartamente a existência de uma preferência eleitoral dos "pardos", ou seja, dos mulatos, pela candidatura do herdeiro getulista, ainda que controlando outras variáveis explicativas, como a situação sócio-econômica, o grau de urbanização, etc.

Também Mônica Castro (1992), a partir de dados de intenção de votos em quatro municípios brasileiros de porte médio, para as eleições de 1989, comprova a existência de especificidade do voto negro. Um voto que opera complexamente acoplado à situação sócio-econômica: entre os mais pobres, os negros tendem à apatia política (não comparecimento às urnas, voto nulo), enquanto que, entre os mais bem situados economicamente, os negros tenderiam a votar na esquerda. Castro não encontra, todavia, diferenças significativas de comportamento entre pardos e pretos.

Se, como vimos, a preferência dos negros pelo Imperador e pelo populismo getulista é interpretada por Gilberto Freyre (1956) como produto do seu sentimento de insegurança e como busca de proteção social em figuras fortes e dominadoras, Souza (1971) e Andrews (1991), entretanto, sugerem que tal preferência tinha sólidas bases e contrapartidas materiais. No caso do populismo, Souza (1971, p. 64) argúi, por exemplo, que as leis trabalhistas de Vargas deram ao negro brasileiro as garantias para a sua inclusão na sociedade de classes. Seus dados mostram, ademais, que, entre os jovens eleitores de 1960, havia uma maior mobilidade ascendente entre os negros que entre os brancos, ainda que essa maior mobilidade, todavia, fosse insuficiente para erodir a identificação dos negros com a classe trabalhadora e os pobres. No plano ideológico, "pelo menos durante os primeiros anos do período de democracia liberal, de 1945 a 1964, as categorias políticas de negro e povo eram quase que intercambiáveis".

Também Reginaldo Prandi interpretando esse período, diz: "Mas é a feição populista do trabalhismo de Vargas que explicaria a adesão do negro a essa corrente partidária e seus candidatos. O populismo nega a luta de classes e dilui as raças numa unidade homogênea, o povo, que é ideologicamente a fonte de toda a legitimidade. Diferenças raciais não fazem sentido, como não faz sentido qualquer movimento de afirmação racial; o populismo, assim, é uma ideologia de integração do negro como igual" (Prandi, 1996, p. 63-64).

Depois da Constituição de 1988, que permite o voto de analfabetos, incorporando assim milhões de negros ao eleitorado brasileiro, e diante do avanço do Movimento Negro no país pregando o voto em candidatos negros, a relação entre raça e política voltou a preocupar os cientistas políticos. O lançamento da candidatura de Benedita da Silva ao governo do estado do Rio de Janeiro, em 1989, com a polarização racial e de classe que se seguiu, assustou as elites políticas, econômicas e intelectu- 
ais do país. Estaríamos em vias de assistir à racialização da política brasileira? Estariam os negros no Brasil desenvolvendo sentimentos e comportamentos políticos comunitários ${ }^{5}$ ?

Berquó e Alencastro (1992), analisando dados de pesquisas amostrais realizadas em São Paulo e em Vitória do Espírito Santo, vêem a possibilidade, com o fim da proibição de voto aos analfabetos, de surgir no país o voto étnico negro, ou seja uma preferência dos afro-descendentes em votar em candidatos que representem a comunidade negra brasileira, ainda que apenas $14 \%$ dos que se auto-classificam de negros manifestem tal intenção. $\mathrm{O}$ voto étnico até então estivera restrito a comunidades étnicas de São Paulo (italianos, sírio-libaneses, portugueses, japoneses, etc.) e Rio de Janeiro (portugueses).

Analisando dados de intenção de votos para as eleições de 1994, Prandi (1996) também constata a preferência eleitoral dos negros por alguns candidatos (Lula, Brizola, Quércia) em detrimento de outros (FHC, Amin, Enéas), ainda que controlando variáveis como área geográfica, idade, sexo, renda, escolaridade. Mais ainda, a cor, para Prandi, foi o fator principal para a predição da intenção de voto, superando a escolaridade ou a idade. Prandi rejeita, contudo, as interpretações de Souza, Castro, Berquó e Alencastro, Silva e Soares, segundo as quais tratar-se-ia de um voto motivado ideológica ou etnicamente, preferindo retornar a uma explicação mais próxima da de Freyre: tratar-se-ia de um sentimento profundo de desamparo e de impotência, que levaria os negros a identificar-se com os programas de alguns candidatos carismáticos.

Mas, se do ponto de vista da política eleitoral, não parece ter havido, nos últimos 15 anos, uma movimentação dos negros em uma direção única, isso não impediu a formação de um movimento social relativamente forte.

\section{Os movimentos negros}

Neste item, vamos falar de comportamentos radicais, ou seja, aqueles que quebram as regras do conformismo social. Por isso, antes de começar, vale a pena, em breve parágrafos, ressaltar as regras que definem tal conformismo.

A "democracia racial" pode também ser vista como a institucionalização de um sistema de orientação de ação (práticas, expectativas, sentidos e valores arraigados no senso comum). Desta perspectiva, os negros e mulatos agiriam, no Brasil, de tal maneira que sua cor não seria um fator relevante da organização de sua conduta e do entendimento desta. Não que essas pessoas não percebessem qualquer discriminação social, mas esta, quando existente, não seria atribuída à raça e, caso fosse, seria vista como episódica e marginal. Um negro poderia, assim, comportar-se normalmente e seguir, também normalmente, uma determinada trajetória social, sem que sua cor fosse responsabilizada por esta trajetória. Tal "normalidade" seria garantida, obviamente, por um padrão universal de comportamento. Ou seja, um padrão "brasileiro", mais que "branco". A crença na existência e na efetividade desse
5 De fato, políticos negros, tais como Albuíno Azeredo, no Espírito Santo, e Alceu Colares, no Rio Grande do Sul, já haviam sido eleitos anteriormente governadores de seus estados. A diferença desses políticos, em relação a Benedita, é que se tratava de políticos "conformistas": eram ambos de partidos políticos não radicais $\mathrm{e}$ pessoas "bem educadas", no sentido de se expressarem em "bom" português de classe média e acreditarem nos valores da "democracia racial", sem apelarem diretamente para o voto negro. Mais adiante, ficará claro no que consiste o "conformismo" desses políticos. 
comportamento seria responsável pela generalização de trajetórias bem-sucedidas de negros e mulatos na sociedade brasileira, ainda quando estas pessoas pudessem reconhecer que efetivamente sofreram constrangimentos e humilhações por conta de sua cor. O que faria este comportamento efetivo não seria a ausência de discriminação, mas o fato de esta não ser realçada ou considerada um obstáculo insuperável.

A crença, pelas ciências sociais, de que tal comportamento de negros e mulatos seja efetivo e generalizado não se dá, entretanto, sem contradições. Roger Bastide, por exemplo, se referiu a tal comportamento como "embranquecimento", realçando justamente seu caráter aculturado, que distanciava o negro de sua cultura e de seus valores. Ou seja, evocando uma certa inautenticidade naquilo que esses negros consideravam "brasileiro" e que ele, Bastide, implicitamente, considerava "branco". Do mesmo modo, era considerado "embranquecimento" a absorção pelos negros de certos padrões de comportamento das classes médias e altas, o que significava, também subrepticiamente, que não haveria lugar para negro nessas classes.

Pode-se dizer, baseado nessa literatura dos anos 50 e 60, que havia dois tipos de "negro": o que acreditava na "democracia racial", ou seja, o "embranquecido" ou racialmente "alienado", e o negro consciente de sua cor e de sua discriminação, que Fernandes e Bastide chamaram de "o novo negro".

Estudos recentes (Figueiredo, 1999) têm demonstrado que no período atual, além destes dois tipos, existe um outro: o negro que, mesmo sabendo que sua cor faz parte do jogo permanente das representações sociais, definindo oportunidades desiguais, faz, ainda assim, uma trajetória de ascensão social sem a necessidade de mobilizar politicamente a cor. Este seria o novo conformismo negro, que grassaria no espaço delimitado pelos valores da democracia racial, sem confundir-se com os "embranquecidos", e no espaço cultural construído pela militância negra, mas sem confundir-se politicamente com esta.

Mas, vamos ao ponto.

O protesto negro no Brasil moderno, isto é, de 1930 para cá, tem crescido nos momentos de mais forte tensão no tecido nacional. Nos anos 30, em São Paulo, por exemplo, as diversas formações étnicas - principalmente os italianos, os sírios-libaneses, os portugueses - estavam tão bem organizadas que os brasileiros de variada mestiçagem e os negros sentiam-se ameaçados de exclusão; enquanto o regionalismo paulista assumia contornos separatistas.

É nessa época que surge a Frente Negra Brasileira (FNB), uma organização étnica, no sentido de que cultivava valores comunitários específicos, mas cuja forma de recrutamento e identificação era a "cor" ou a "raça" e não a "cultura" ou as "tradições". Ao contrário, a FNB buscava justamente afirmar o negro como "brasileiro", renegando as tradições culturais afro-brasileiras, responsabilizadas pelos estereótipos que marcavam os negros, e denunciando o preconceito de cor que alijava os brasileiros negros do mercado de trabalho em favor dos estrangeiros (Bastide 1955, 1983; Fernandes 1955, 1965). Mas a FNB foi, também, uma organização política que chegou a transformar-se em 
partido, antes de ser extinta pelo Estado Novo. Politicamente, apesar de conter algumas dissidências socialistas, a FNB era majoritariamente de direita, de corte fascista, incluindo mesmo um grupamento paramilitar. Assim, em 1932, os negros relutam em formar com a revolução constitucionalista paulista, de cunho regionalista e separatista e, em 1937, apóiam o golpe de Vargas que, de certo modo, implementa algumas políticas ao encontro das suas reivindicações. Tratava-se, portanto, do protesto negro contra uma organização social (a da Primeira República) que tinha material e culturalmente acuado as populações negras e mestiças em espaços secundários e marginais.

Mas a ditadura de Vargas prescindia de organizações políticas livres, ainda que sua política tivesse o respaldo das massas. O protesto negro só poderá emergir com a restauração das liberdades civis, sete anos depois.

A redemocratização em 1945 será marcada, como vimos, por um forte projeto nacionalista, tanto em termos econômicos quanto culturais. Isso representou, por um lado, a recusa do liberalismo econômico e do imperialismo cultural europeu e americano e, por outro lado, a edificação de um capitalismo regulado pelo estado e uma cultura nacional autóctone de bases populares. Esse projeto de nação ofereceu aos negros uma melhor inserção econômica e transformou em nacionais ou regionais brasileiras as diversas tradições culturais de origem africana ou luso-afro-brasileira: o barroco colonial de Pernambuco, Bahia e Minas, as procissões católicas, as festas de largo, o samba, o carnaval, a capoeira, o candomblé, as congadas, as diversas culinárias regionais, etc. Ou seja, o federalismo político foi, de certo modo, fortalecido pela nacionalização dos diversos regionalismos culturais, todos de cunho racial, e temperados agora pela grande mobilidade espacial da população e pela "integração dos negros na sociedade de classes", ou seja integrados como trabalhadores e como brasileiros negros. O Brasil, se não era de fato, deveria ser, no devir, uma democracia racial, coisa que, aliás, para o imaginário nacional bastava.

O protesto negro, entretanto, não desapareceu, muito pelo contrário, ampliou-se e amadureceu intelectualmente nesse período. Primeiro, porque a discriminação racial, à medida que se ampliavam os mercados e a competição, também se tornava mais problemática; segundo, porque os preconceitos e os estereótipos continuavam a perseguir os negros; terceiro, porque grande parte da população negra continuava marginalizada em favelas, mucambos, alagados e na agricultura de subsistência. Serão justamente os negros em ascensão social, aqueles recentemente incorporados à sociedade de classes, que verbalizarão com maior contundência os problemas da discriminação, do preconceito e das desigualdades.

O Teatro Experimental do Negro (TEN) do Rio de Janeiro foi, nesse período, a principal organização negra do país. De cunho eminentemente cultural, de início, seu projeto de abrir o campo das artes cênicas brasileiras aos atores negros acabou se ampliando num projeto de formação profissional, de psicodrama coletivo da população negra e de recuperação da imagem e da autoestima dos negros brasileiros. Seus principais intelectuais, Abdias do Nasci- 
mento $(1950,1968)$ e Alberto Guerreiro Ramos (1957), principalmente este último, foram mais longe em sua crítica ao imperialismo cultural europeu e norte-americano, pregando uma ciência social que se engajasse num projeto de construção nacional. Para Guerreiro Ramos, negro era o povo brasileiro, não fazendo sentido falar de uma "questão negra" ou cultivar como exóticas formas de expressão culturais próprias da situação de miséria e de ignorância em que se encontrava boa parte da população pobre do país (como se referia principalmente às religiões afro-brasileiras). Os intelectuais do TEN e a sua ideologia estiveram, portanto, em sintonia com a política nacionalista e populista da época, cuja expressão maior foi o trabalhismo de Vargas. Do ponto de vista ideológico, radicalizando o mulatismo de Gilberto Freyre, segundo o qual todo brasileiro traria na alma a marca da mestiçagem, Guerreiro Ramos transforma a negritude em assunção de uma identidade nacional brasileira liberta dos complexos de inferioridade deixados pela colonização portuguesa ${ }^{6}$.

Depois de um novo período repressivo, que adormece a sociedade civil entre 1964 e 1978, o protesto negro recupera toda a sua veemência no período atual, marcado pelo Movimento Negro Unificado (MNU).

Fundado em 1979, o MNU tem um perfil radicalmente diferente de seus antecessores (Gonzalez, 1982; Santos, 1985). Politicamente, alinha-se à esquerda revolucionária; ideologicamente, assume, pela primeira vez no país, um racialismo radical. Suas influências mais evidentes e reconhecidas são: primeiro, a crítica de Florestan Fernandes à ordem racial de origem escravocrata, que a burguesia brasileira mantivera intacta e que transformara a democracia racial em mito; segundo, o movimento dos negros americanos pelos direitos civis e o desenvolvimento de um nacionalismo negro nos Estados Unidos; terceiro, a luta de libertação dos povos da África meridional (Maçambique, Angola, Rodésia, África do Sul). Mas, a esses se deve juntar pelo menos mais três: o movimento feminista internacional, que possibilita a emergência de uma militância feminina negra; o novo sindicalismo brasileiro, que leva o protesto aos chãos-de-fábrica e retira as lideranças da órbita dos partidos políticos tradicionais; e os novos movimentos sociais urbanos, que mantêm a sociedade civil mobilizada, durante toda a década de 80 .

\section{A ideologia do protesto negro nos anos 80: o quilombismo.}

${ }^{6}$ Ver, sobre esse assunto, Bastide (1961).
O Movimento Negro Unificado dos anos 80 foi um movimento cindido entre, de um lado, lideranças de esquerda, geralmente jovens universitários, algumas delas sintonizadas com a luta democrática que se organizava a partir das organizações socialistas que se abrigavam no PMDB e, de outro lado, lideranças sintonizadas com a resistência cultural que espontaneamente se espraiava nos meios negros mais pobres, influenciados pela cultura de consumo de massa. A presença de uma liderança histórica, como Abdias do Nascimento, com trânsito internacional, ligado ao trabalhismo de Brizola, foi também decisiva na formação ideológica do movimento. Por uma questão de es- 
paço, limitar-me-ei aqui a examinar o "quilombismo", doutrina forjada por Abdias, uma das matrizes ideológicas que permeava o movimento negro nos anos 80, aliando radicalismo cultural a radicalismo político.

Duas influências maiores marcam a doutrina de "quilombismo" em Abdias do Nascimento. A mais óbvia é certamente o Afro-centrismo que foi, nos anos 70, uma doutrina muito influente nos meios negros anglo-saxônicos (e não apenas norte-americanos), alimentado principalmente por intelectuais africanos da Nigéria e Gana, radicados nos Estados Unidos. Vem do Afrocentrismo o projeto de filiar os negros brasileiros a uma "nação" negra transnacional, de cuja matriz teria evoluído a civilização ocidental, cujas raízes mais profundas se encontram no antigo Império egípcio e na presença africana na América pré-colombiana. Trata-se, evidentemente, de um movimento, ao mesmo tempo, de invenção de tradições e reivindicação de um processo civilizatório negro. A outra influência foi, sem dúvida, o marxismo, principalmente através de sua vertente mais ligada ao nacionalismo brasileiro dos anos 60. Desse nacionalismo marxista, Abdias retira não apenas analogias formais e palavras de ordem, mas a idéia fundamental de que a emancipação do negro brasileiro significa a emancipação de todo o povo brasileiro da exploração capitalista. Ora, o caráter universalista da emancipação dos negros no Brasil está intimamente ligado à idéia de uma luta de maioria explorada, e não de uma minoria oprimida, como nos Estados Unidos. Para esta luta, a definição ampla de negro como descendentes de africanos (e não apenas pessoas de cor ou fenótipo negros) é imprescindível. Aliás, tal definição ampliada de negro já fora feita por Guerreiro Ramos e pelo próprio Abdias ${ }^{7}$ quando, nos anos 50, se apropriaram das idéias de negritude, vindas então do mundo francófono, principalmente do Senegal e das Antilhas, e muito influente em Paris. Naquela oportunidade, como bem argumentou Roger Bastide (1961), os negros brasileiros deram um sentido bastante original ao movimento da negritude, recusando seus aspectos culturais (vistos então, no caso do Brasil, como anacronismo bárbaro) e enfatizando seu caráter libertário e nacionalista. A novidade, nos anos 80, foi a adoção de uma postura, a um só tempo, nacionalista e culturalista.

A adoção de uma classificação racial bipolar (brancos e negros, abolindo as categorias intermediárias de "pardo" ou "moreno") parece, portanto, ter uma motivação claramente política. Longe de ser produto de mentes "colonizadas" pelo imperialismo cultural americano ou presas a um racialismo arcaico $^{8}$, foi a escolha de um movimento que optou por uma luta em que o negro pudesse ser assimilado à classe trabalhadora explorada e não a uma minoria apenas oprimida.

Como todo movimento político, o movimento negro se nutre de tradições e de elos com movimentos contemporâneos, internos e externos ao país, retirando daí a sua atualidade e eficácia ideológica. Foi o que fizeram as suas principais lideranças intelectuais e políticas, como Abdias do Nascimento e Lélia Gonzalez.
Ainda que haja alguma continuidade entre o pensamento de Abdias dos anos $50 \mathrm{e}$ o dos anos 80 , é preciso ter bem claro que o seu pensamento, entre 1960 e 1980, se desloca do eixo da "negritude" para o do "afro-centrismo".

${ }^{8}$ Aliás, a distância que o movimento negro guarda da noção biológica de "raça" é reiterada inúmeras vezes (cf. Nascimento, 1980, p. 163): "Aviso aos caluniadores, intrigantes, maliciosos e os apressados em julgar: a palavra 'raça', no sentido em que a emprego, é definida em termos de história e cultura, não de pureza biológica". 
Tomemos, para exemplificar, o quilombismo de Abdias do Nascimento. Em sua referência interna, Abdias buscou integrar o programa do quilombismo ao movimento pela redemocratização do país, através de uma luta de emancipação radical, de inspiração marxista (Quadro 1, item A).

Do mesmo modo, Abdias definiu o negro brasileiro não apenas como a parcela mais explorada do povo brasileiro, mas sua maioria, mobilizando velhas tradições sobre o mulatismo dos capitães-do-mato, perseguidores dos quilombolas (Quadro 1, item B). Mais. Abdias forçava a analogia entre a luta dos negros brasileiros e a luta contra o apartheid na África do Sul, definindo o negro como o trabalhador por excelência, o mais brasileiro dos brasileiros, a maioria oprimida por uma minoria racista, em grande parte estrangeira (Quadro 1, item C).

Forçando os aspectos de segregação residencial, exclusão do mercado formal de trabalho e terrorismo policial, Abdias aproxima, por analogia, o racismo brasileiro do sul-africano (Quadro 1, item D). Mas, ao mesmo tempo, a referência à brutalidade policial está também indissoluvelmente ligada ao movimento pelos direitos humanos que, nessa época, já mobilizava as forças políticas que lutavam pela redemocratização do país. Mais claramente, Abdias argúi que, para os negros, o autoritarismo e ausência de direitos têm sido permanentes (Quadro 1, item E). A saída, para Abdias, seria a luta antiimperialista e nacionalista, articulada com movimentos de libertação nacionais e de luta de classes, mas guardando as particularidades culturais e especificidades dos negros brasileiros, vis-à-vis seja outros negros na diáspora, seja à classe operária brasileira (Quadro 1, item F).

Uma análise do texto clássico de Lélia Gonzalez e dos documentos do MNU encontraria os mesmos elementos, ainda que de modo não tão explícito: o movimento negro brasileiro se nutre ideologicamente das lutas de emancipação que naquele momento estão travando alguns povos negros (nos Estados Unidos, na África do Sul e na África portuguesa) e da tradição das lutas de resistência popular no Brasil, do abolicionismo ao Teatro Experimental do Negro.

\section{Os limites da cooptação}

Assim, como nos dois períodos anteriores (1930-1937, 1945-1964), o protestonegro forma-se num ambiente de efervescência intelectual e de mobilização política intensa da sociedade brasileira. Mas, ao contrário da FNB e do TEN, que encontraram rapidamente uma resposta às suas reivindicações no quadro da política tradicional, seja através do golpe do Estado Novo, seja através do trabalhismo de Vargas e do nacionalismo, oradicalismo do MNU faz com que o protesto negro atual tenha uma sobrevida maior. Ademais, o MNU é apenas uma entre as muitas organizações negras que foram fundadas nos últimos quinze anos. Logo emergiram outras organizações, de diferentes matizes ideológicos e políticos, e com diferentes finalidades, entre as quais se destacam entidades culturais, políticas e jurídicas, que têm em comum a luta contra o racismo. 
De fato, o movimento negro recente trouxe para a cena brasileira uma agenda que alia política de reconhecimento (de diferenças raciais e culturais), política de identidade (racialismo e voto étnico), política de cidadania (combate à discriminação racial e afirmação dos direitos civis dos negros) e política redistributiva (ações afirmativas ou compensatórias).

Uma pequena lista das reivindicações do movimento negro, nos últimos quinze anos, dá uma idéia de sua abrangência e radicalismo. Em primeiro lugar, o MNU recusou a data oficial de celebração da incorporação dos negros à nação brasileira, o 13 de maio, data da abolição da escravidão, passando a festejar o 20 de novembro, dia da morte de Zumbi, que chefiou a resistência do quilombo dos Palmares em 1695; em segundo lugar, passou a reivindicar uma mudança completa na educação escolar, de modo a extirpar dos livros didáticos, dos currículos e das práticas de ensino os estereótipos e os preconceitos contra os negros, instilando, ao contrário, a auto-estima e o orgulho negros; em terceiro lugar, exigiu uma campanha especial do governo brasileiro que esclarecesse a população negra (pretos e pardos) de modo a se declarar "preta" nos censos demográficos de 1991 e 2000; em quarto lugar, reclamou e obteve a modificação da Constituição para transformar o racismo em crime inafiançável e imprescritível, tendo, posteriormente, conseguido passar legislação ordinária regulamentando o dispositivo constitucional; em quinto lugar, articulou uma campanha nacional de denúncias contra a discriminação racial no país, pregando e alcançando, em alguns lugares, a criação de delegacias especiais de combate ao racismo; finalmente, concentra-se, hoje em dia, em reclamar do governo federal a adoção de políticas de ação afirmativa para o combate das desigualdades raciais.

Algumas de suas reivindicações encontraram respostas rápidas por parte do estado brasileiro, tais como as que poderiam mais facilmente caber na atual matriz de nacionalidade, cujo teor é o do sincretismo das três raças fundadoras. Aliás, foi a partir da compreensão muito peculiar da multirracialidade e do multiculturalismo como síntese (à maneira freyreana), e não como convivência entre iguais (à maneira norte-americana), que os brasileiros passaram a aceitar algumas teses do movimento negro, tais como o respeito às tradições e às expressões culturais de origem africana e à estética negra. $\mathrm{O}$ fato é que também o estado brasileiro foi ágil em responder nesse diapasão, através da criação de fundações culturais (a Fundação Palmares, por exemplo), criação de conselhos estaduais da comunidade negra, incorporação de símbolos negros (como a transformação de Zumbi em herói nacional e o reconhecimento oficial do 20 de novembro como o Dia do Negro); desenvolvimento de legislação mais apropriada de combate ao racismo (a Constituição de 1988 e as leis 7.716 e 9.459, que regulamentam o crime de racismo); modificação do currículo escolar, em alguns municípios onde a pressão e a presença negra são mais fortes, para permitir a multiculturalidade.

Outras demandas, entretanto, como aquelas que dizem respeito ao combate das desigualdades raciais na distribuição de renda e no acesso aos serviços públicos, que exigem políticas afirmativas e inovadoras, encontram, 
ainda hoje, grande resistência. Isso é verdade, ainda que, aos poucos, novas instituições estejam sendo criadas para atender a tais demandas, tais como: os cursinhos pré-vestibulares para negros e carentes, a isenção de taxas de inscrição no vestibular para alunos provenientes de tais cursos, projetos de lei que reservam vagas nas universidades públicas para estudantes egressos do sistema público de educação, introdução de quesitos sobre cor nos formulários e registros de instituições de ensino superior, etc.

A amplitude das demandas tem garantido, portanto, a alimentação contínua do ativismo político negro em maior grau que o de sua cooptação. Do mesmo modo, palavras de ordem como o voto étnico (negro deve votar em negro) e o cultivo da consciência negra (de corte racialista) dificilmente podem ser bem absorvidas. O que tem acontecido, em contrapartida, é que o perfil ideológico e partidário dos ativistas negros tem se diversificado rapidamente, devido à cata deliberada de todos os partidos pelo eleitorado negro. Em certos momentos, entretanto, líderes negros de grande carisma, como foi o caso de Benedita da Silva, no Rio de Janeiro, em 1989, surgiram, e podem voltar a surgir, no cenário político, disputando cargos eletivos por partidos de esquerda, como foi o caso do PT ou do PDT, e, através da conjunção de propostas radicais de modificação das desigualdades raciais, ameaçarem desestabilizar o sistema.

Quero, finalmente, desenvolver ainda alguns dos outros motivos porque o protesto negro atual tem sido mais duradouro e mais difícil de ser absorvido pelo estado. Além dos motivos que já insinuei (crise da identidade nacional, radicalismo e abrangência das reivindicações negras), tem-se agora uma nova conjuntura internacional em que o estado brasileiro já não pode mais se isolar parcialmente, seja em termos econômicos, seja em termos culturais e políticos.

Em termos do esforço de absorção do protesto e cooptação de quadros, a ação do estado teve que se limitar à criação de fundações e alguns conselhos estaduais, enquanto os partidos políticos procuravam trazer para os seus programas algumas das reivindicações e alguns políticos negros (Pereira, 1982). Mas partidos e instituições governamentais incorporam apenas parte das lideranças negras, ou seja, aquelas afiliadas ou simpatizantes dos partidos no poder, deixando de fora tanto as lideranças de oposição, quanto a militância partidariamente independente. Esta última, aliás, tem sido muito ativa, agrupada em organizações não-governamentais e financiadas por doações internacionais. Tanto o escopo dessas organizações, que têm o ativismo como profissão, quanto sua fonte de financiamento garantem-lhes maior autonomia e radicalidade de ações e propostas. Ademais, essas entidades não só cooperam, mas também competem entre si pela representação étnica. Em segundo lugar, a sociedade de consumo e a internacionalização da indústria cultural possibilitaram o surgimento de movimentos culturais negros, influenciados não apenas pela cultura popular brasileira de origem africana, mas também pela cultura do black atlantic. Movimentos como os que congregam principalmente a juventude urbana - o funk carioca (Vianna, 1988), o bloco afro 
baiano (Risério 1981), o reggae maranhense (Silva, 1995), o rap paulista (Félix, 2000) - são movimentos independentes de qualquer organização política ou étnica, alguns deles bastante radicais em seu protesto, o que acaba por forçar as lideranças políticas negras a correr atrás.

\section{Conclusões}

Procurei, nesse artigo, desenvolver uma compreensão original do estado das relações entre brancos e negros no Brasil, a partir da reinterpretação do que seja a "democracia racial" brasileira. Entendida como uma ideologia de dominação por Fernandes (1965), o mito da democracia racial no Brasil seria apenas um modo cínico e cruel de manutenção das desigualdades sócio-econômicas entre brancos e negros, acobertando e silenciando a permanência do preconceito de cor e das discriminações raciais. É desse modo que a maioria dos intelectuais negros brasileiros entende a "democracia racial" e faz da denúncia de sua crueldade (tal ideologia anestesia e aliena suas vítimas) o principal instrumento de mobilização política e de formação de uma identidade racial combativa.

Contra tal interpretação têm-se manifestado alguns antropólogos (Fry, 1995), que argúem que a "democracia racial" é propriamente um mito fundador da nação brasileira, ou seja, parte fundamental de sua matriz civilizatória, a qual, ainda que não exclua completamente preconceitos e discriminações, permite maior intimidade e interpenetração entre negros e brancos, fornecendo bases mais sólidas para a superação do racismo.

Meu entendimento é que devemos ver na "democracia racial" um compromisso político e social do moderno estado republicano brasileiro, que vigeu, alternando força e convencimento, do Estado Novo de Vargas até o final da ditadura militar. Tal compromisso consistiu na incorporação da população negra brasileira ao mercado de trabalho, na ampliação da educação formal, enfim na criação das condições infra-estruturais de uma sociedade de classes que desfizesse os estigmas criados pela escravidão. A imagem do negro enquanto povo e o banimento, no pensamento social brasileiro, do conceito de "raça", substituído pelos de "cultura" e "classe social", são as expressões maiores desse compromisso.

A redemocratização brasileira, a partir da década de 1980, tem procurado atualizar tal compromisso, mas vem encontrando dificuldades crescentes. Em primeiro lugar, são as desigualdades raciais mesmas que passaram a ser objeto de denúncia e motivo de reivindicações políticas, e não apenas o preconceito ou a discriminação; em segundo lugar, a formação da identidade negra tem exigido a adoção de políticas multiculturais ou multirraciais que ultrapassem o reconhecimento pelo estado da divisão da sociedade em classes (que marcou o pacto da "democracia racial"); em terceiro lugar, porque a mobilização negra, no Brasil, não segue o padrão de uma política de minorias, mas, tendo como base, justamente, a idéia de que o povo brasileiro é negro (Ramos, 1957), aspira à emancipação de uma maioria explorada. 


\section{Quadro 1}

\section{Alguns elementos ideológicos do Quilombismo}

\begin{tabular}{|c|c|}
\hline 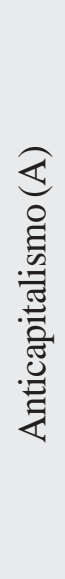 & $\begin{array}{l}\text { "0 povo negro tem um projeto coletivo: a edificação de } \\
\text { uma sociedade fundada sobre a justiça, a igualdade e o respeito por } \\
\text { todos os seres humanos; uma sociedade cuja natureza intrínseca tor- } \\
\text { ne impossível a exploração econômica ou racial. Uma democracia } \\
\text { autêntica, fundada pelos destituídos e deserdados da terra. Não te- } \\
\text { mos interesse na simples restauração de tipos e formas obsoletas de } \\
\text { instituições econômicas, políticas e sociais; isto serviria apenas para } \\
\text { procrastinar o advento de nossa emancipação total e definitiva, a qual } \\
\text { virá apenas com a transformação radical das estruturas socioeco- } \\
\text { nômicas e políticas existentes. Não temos interesse em propor uma } \\
\text { adaptação ou reforma dos modelos da sociedade capitalista" (Nasci- } \\
\text { mento, 1980, p. 160). }\end{array}$ \\
\hline 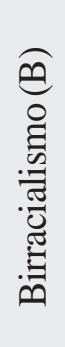 & $\begin{array}{l}\text { "A citação dos capitães-do-mato é importante. De um modo } \\
\text { geral, eles eram mulatos, isto é, negros de pele clara assimilados pela } \\
\text { classe dominante branca e instigados contra seus irmãos e irmãs afri- } \\
\text { canos. Não devemos hoje permitir que nos dividam entre 'pretos' e } \\
\text { 'mulatos', enfraquecendo nossa identidade fundamental de afro-bra- } \\
\text { sileiros, afro-americanos de todo o continente, isto é, africanos na } \\
\text { diáspora" (Nascimento, 1980, p. 156). }\end{array}$ \\
\hline 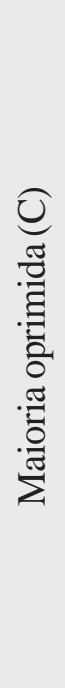 & $\begin{array}{l}\text { "Junto com os índios, escravizados por um período e de- } \\
\text { pois exterminados, os africanos foram o primeiro e único trabalha- } \\
\text { dor durante três séculos e meio, construindo as estruturas desse país } \\
\text { chamado Brasil. É desnecessário lembrar mais uma vez os vastos } \\
\text { campos que os africanos irrigaram com seu suor, ou evocar os cana- } \\
\text { viais, os campos de algodão, as minas de ouro, diamante e prata, e as } \\
\text { muitas outras fases da formação do Brasil alimentadas com o sangue } \\
\text { martirizado dos escravos. O negro, longe de ser um invasor ou um } \\
\text { estrangeiro, é a verdadeira alma e corpo deste país. Entretanto, ape- } \\
\text { sar desse fato histórico irrefutável, os africanos e seus descendentes } \\
\text { nunca foram tratados como iguais pela minoria branca que } \\
\text { complementa o quadro demográfico do país, mesmo nos dias de hoje. } \\
\text { Esta minoria manteve um monopólio exclusivo de todo o poder, bem } \\
\text { estar, saúde, educação e renda nacionais" (Nascimento, 1980, p. 149). }\end{array}$ \\
\hline
\end{tabular}




\begin{tabular}{|c|c|}
\hline 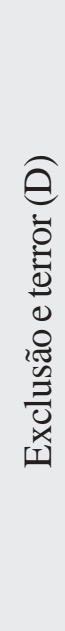 & $\begin{array}{l}\text { "A condição do povo negro não mudou desde então, senão } \\
\text { que piorou. Posto à margem do emprego, largado em situação de semi- } \\
\text { emprego ou subemprego, o povo negro continua largamente excluído } \\
\text { da economia. A segregação residencial é imposta à comunidade negra } \\
\text { pelo duplo fator da raça e da pobreza, marcando como áreas residenciais } \\
\text { negras guetos de diversas denominações: favelas, alagados, porões, } \\
\text { mocambos, invasões, conjuntos populares ou 'residenciais'. A brutali- } \\
\text { dade policial permanente e as prisões arbitrárias motivadas racialmente } \\
\text { contribuem para o reino de terror sob o qual vivem cotidianamente os } \\
\text { negros. Nessas condições, compreende-se porque nenhum negro cons- } \\
\text { ciente tem esperança que mudanças progressivas possam ocorrer es- } \\
\text { pontaneamente e beneficiar a comunidade afro-brasileira" (Nascimento, } \\
\text { 1980, p. 149-150). }\end{array}$ \\
\hline 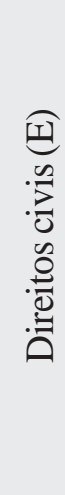 & $\begin{array}{l}\text { "Quase } 500 \text { anos de autoritarismo é bastante. Não pode- } \\
\text { mos, não devemos e não toleraremos mais. Uma das práticas básicas } \\
\text { deste autoritarismo é o desprezo brutal da polícia pela família negra. } \\
\text { Todo tipo de arbitrariedade é fixada indelevelmente nas batidas polici- } \\
\text { ais rotineiras que mantêm a comunidade negra aterrorizada e desmo- } \\
\text { ralizada. Com estas batidas, espancamentos, assassinatos e tortura, a } \\
\text { impotência e 'inferioridade' do povo negro é atualizada diariamente, } \\
\text { posto que incapazes de defenderem-se a si mesmos ou de proteger a } \\
\text { sua família e os membros de sua comunidade. Isto constitui uma situ- } \\
\text { ação de humilhação perpétua" (Nascimento, 1980, p. 162). }\end{array}$ \\
\hline 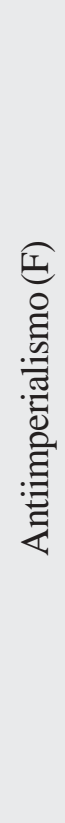 & $\begin{array}{l}\text { "Nessa passagem, os autores [do manifesto] tocam num } \\
\text { ponto importante, a tradição quilombista - a definição do caráter naci- } \\
\text { onalista do movimento. Nacionalismo aqui não deve ser confundido } \\
\text { com xenofobia. O quilombismo é uma luta antiimperialista, que se } \\
\text { articula com o pan-africanismo e sustenta uma solidariedade radical } \\
\text { com todos os povos do mundo que lutam contra a exploração, a opres- } \\
\text { são e a pobreza, tanto quanto contra as desigualdades motivadas por } \\
\text { raça, cor, religião ou ideologia. O nacionalismo negro é universalista e } \\
\text { internacionalista porque apóia a libertação nacional dos povos e vê no } \\
\text { respeito à sua singularidade cultural e à sua integridade política um } \\
\text { imperativo para a libertação mundial. A uniformidade sem face em } \\
\text { nome da 'unidade' ou da 'solidariedade', em conformidade com os } \\
\text { ditames do modelo social ocidental, não é do interesse dos povos opri- } \\
\text { midos não-ocidentais. O quilombismo, enquanto movimento naciona- } \\
\text { lista, ensina que a luta de cada povo por sua libertação deve estar } \\
\text { enraizada na sua própria identidade cultural e experiência histórica" } \\
\text { (Nascimento, 1980, p. 155). }\end{array}$ \\
\hline
\end{tabular}


KEY WORDS: racial democracy, black movement, racial question, Brazil.
ABSTRACT: In this article, I analyze how the racial question has marked Brazilian politics in the past fifteen years. I start by showing what the idea of racial democracy meant to the process of reconstruction of the Brazilian nationality, and go on to review the studies on the voting behaviour of the Brazilian Black population and discuss the emergence of Black social movements and their incorporation into the political system. I understand that we must see "racial democracy" as a political and social compromise of the Brazilian modern republican state, which was in power from the Vargas' New State until the end of the military dictatorship. This compromise which at present is in crisis, consisted of the incorporation of the Brazilian Black population into the work market, of the expansion of formal education, in other words, of the making of the infra-structural conditions of a society of classes that would do away with the stigmas created by slavery. The image of the Black person as one of the people and the banishment from Brazilian social thought of the concept of "race" which was replaced by those of "culture" and "social class" are the main expressions of this compromise.

\section{REFERÊNCIASBIBUOGRÁFICAS}

AndREWs, George. (1991) O protesto político negro em São Paulo - 18881988. Estudos Afro-Asiáticos, (21): 27-48.

BASTIDE, Roger. (1955) Manifestações do preconceito de cor. In: FERnANDES, Florestan \& (orgs.). Relações raciais entre brancos $e$ negros em São Paulo. São Paulo, Unesco-Anhembi, p. 159-192.

. (1961) Variations on negritude. Presence Africaine, 8(36): 83-92.

. (1983) A imprensa negra do Estado de São Paulo. Estudos Afrobrasileiros, São Paulo, p. 129-156.

Berquó, Elza \& Alencastro, Luis F. (1992) A emergência do voto negro. Novos Estudos, Cebrap, 33: 77-88.

Castro, Mônica M. M. de. (1992) Raça e comportamento político. Dados, Rio de Janeiro, 36(3): 469-491.

FELIX, João Baptista de J. (2000) Chic Show e construção de identidade nos bailes black paulistanos. São Paulo, 210 p. Dissertação (Mestrado). Faculdade de Filosofia, Letras e Ciências Humanas da Universidade de São Paulo. 
FERNANDES, Florestan. (1955) A luta contra o preconceito de cor. In: \& BAstide, Roger (orgs.). Relações raciais entre brancos e negros em São Paulo. São Paulo, Unesco-Anhembi, p. 193-226. . (1965) A Integração do negro na sociedade de classes. vol. 2, São Paulo, Dominus Editora.

FigueIREDo, Ângela. (1999) Novas elites de cor: estudo com profissionais liberais negros em Salvador. Salvador, 125 p. Dissertação (Mestrado). Universidade Federal da Bahia.

FreYre, Gilberto. (1933) Casa Grande \& Senzala: formação da família brasileira sob o regime da economia patriarcal. Rio de Janeiro, Schimidt.

(1936) Sobrados e mucambos. Rio de Janeiro, Editora Nacional.

(1956) A escravidão, a monarquia e o Brasil moderno. Revista Brasileira de Estudos Políticos, 1(1): 39-48, dezembro.

FRY, Peter. (1995) O que a cinderela negra tem a dizer sobre a política racial brasileira. Revista USP, (28): 122-135.

GonZALEZ, Lélia. (1982) O movimento negro na última década. In: GonZALEZ, L. \& Hasenbalg, C. Lugar de negro. Rio de Janeiro, Marco Zero, p. 9-66.

Holanda, Sérgio Buarque de. (1936) Raízes do Brasil. Rio de Janeiro, José Olympio.

LAmounier, Bolívar. (1968) Raça e classe na política brasileira. Cadernos Brasileiros, (47): 39-50.

NABuco, Joaquim. (1883) O abolicionismo. Londres, Abraham Kingdon \& Cia.

Nascimento, Abdias do et alli. (1950) Relações de raça no Brasil. Rio de Janeiro, Quilombo. (1968) O negro revoltado. Rio de Janeiro, G.R.D.

(1980) Quilombismo: an Afro Brazilian political alternative. Journal of black studies, 11(2): 141-178, Afro Brasilian Experience and Proposals for Social Change, december.

Pereira, João Baptista B. (1982) Parâmetros ideológicos do projeto político de negros em São Paulo. Revista do Instituto de Estudos Brasileiros, USP, (24): 53-61.

Prado JR., Caio. (1965) A formação do Brasil contemporâneo: colônia. 1ạ edição 1937. São Paulo, Brasiliense.

PRANDI, Reginaldo. (1996) Raça e voto na eleição presidencial de 1994. Estudos Afro-Asiáticos, Rio de Janeiro, (30): 61-78.

Ramos, A. Guerreiro. (1957) Introdução crítica à sociologia brasileira. Rio de Janeiro, Andes. 
Risério, Antonio. (1981) Carnaval Ijexá. Salvador, Corrupio.

Rodrigues, Nina. (1933) Os africanos no Brasil. São Paulo, s/e.

Romero, Silvio. (1949) História da literatura brasileira. 1a edição 1888. $4^{\mathrm{a}}$ edição, Rio de Janeiro, José Olympio.

SANTOS, Joel Rufino dos. (1985) O movimento negro e a crise brasileira. Politica e administração. Rio de Janeiro, 2(2): 287-307, julho-setembro.

Schwarcz, Lilia M. (1993) O espetáculo das raças; cientistas, instituições e questões raciais no Brasil (1870-1930). São Paulo, Companhia das Letras.

. (1999) As barbas do imperador. São Paulo, Companhia das Letras.

Seyferth, Giralda. (1990) Imigração e cultura no Brasil. São Paulo, Brasiliense.

SkIDMORE, Thomas E. (1976) Preto no branco, raça e nacionalidade no pensamento brasileiro. Rio de Janeiro, Paz e Terra.

Silva, Carlos B. Rodrigues. (1995) Da terra das primaveras às ilhas de amor. Reggae, lazer e identidade cultural. São Luis, Edufma.

SILVA, Nelson V. \& SoAREs, Gláucio. (1985) O charme discreto do socialismo moreno. Dados, Rio de Janeiro, 28(2): 253-273.

SouzA, Amaury de. (1971) Raça e política no Brasil urbano. Revista de Administração de Empresas, XI: 61-70, outubro-dezembro.

ViannA, Hermano. (1988) O mundo funk carioca. Rio do Janeiro, Zahar. 